\title{
TANDEM: pedalando juntos em espanhol e português TÁNDEM: Pedaleando juntos en español y portugués
}

\author{
Valdilena Rammé \\ Universidade Federal da Integração Latino-Americana | Brasil \\ val.ramme@gmail.com
}

\section{Resumo}

Este projeto organiza encontros de tandem presencial, onde metade dos participantes fala espanhol como língua materna e a outra metade, português. Para a formação dos tandenistas, contribuímos com um ambiente de prática e aperfeiçoamento de um modelo de aprendizagem autônomo, focado na interação oral e na comunicação. Nossa meta maior, porém, é oferecer à comunidade um espaço para o fortalecimento do bilinguismo português-espanhol, buscado, mais prontamente, na UNILA e, ideologicamente, em toda América Latina. Essa é uma experiência piloto para uma futura institucionalização do tandem como ferramenta complementar de aprendizagem de línguas na Universidade. Assim, fornecemos dados contínuos para uma pesquisa dedicada à sua revisão e aperfeiçoamento.

\section{Palavras-chave}

Tandem; Aprendizagem solidária; Autonomia; Oralidade. 


\section{Introdução}

Um dos maiores desafios dos professores de línguas que trabalham a partir de perspectivas comunicativas e sociointeracionistas é o de criar situações autênticas, ou próximas a isso, para a prática e desenvolvimento das habilidades orais envolvidas no aprendizado de um idioma. Nós, professores, sabemos o quanto é difícil motivar os alunos a falarem em sala de aula. Mais do que isso, sabemos que é somente falando, e falando muito, que o aprendiz realmente progride no aperfeiçoamento dessa competência. Nesse contexto, o tandem se coloca como uma ferramenta didática que pode auxiliar imensamente a professores e alunos.

Mas o que é tandem? De origem latina, essa palavra foi usada pela primeira vez em inglês para se referir àquelas bicicletas de dois lugares (Ilustração 1).

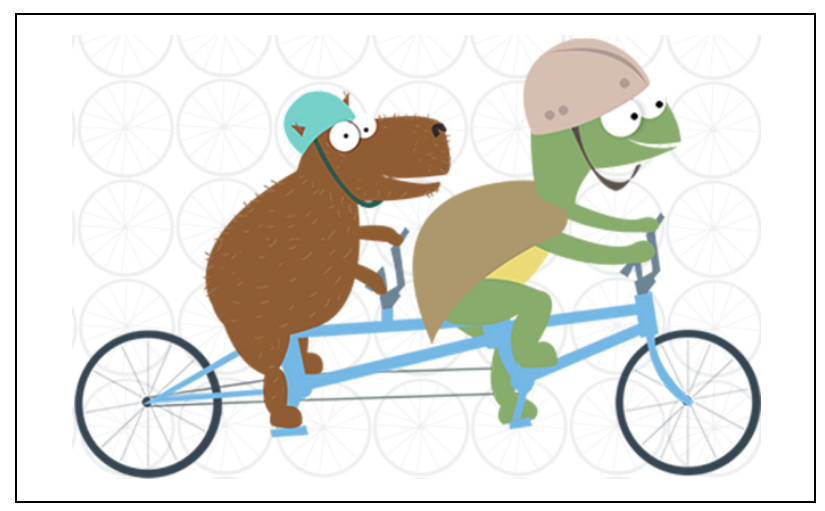

Ilustração 1: Bicicleta tandem

Fonte: tandemunila.com.br (Licença CC-BY-NC)

Mais tarde, em meados do século XX, seu sentido se ampliou para designar trabalhos em cooperação, onde dois ou mais colegas de trabalho ou de empresas se dedicavam a um projeto comum. A Real Academia da Língua Espanhola, de fato, define tandem como "um conjunto de duas pessoas que têm uma atividade comum, ou colaboram em alguma coisa". Foi, então, nos anos 1960 que o termo começou a ser utilizado para designar uma nova estratégia de ensinoaprendizagem em língua estrangeira. Inicialmente implementado na Alemanha, essa atividade ganhou grande popularidade em outros países europeus em pouco tempo (TELLES; VASSALLO, 2006).

E o que isso tem a ver com línguas exatamente? Sempre com a ideia de colaboração entre pessoas de diferentes culturas em mente, esse recurso de aprendizagem consiste em conectar dois estudantes que queiram aprimorar seus conhecimentos na língua estrangeira do outro, ambos ajudando-se mutuamente a se aproximarem da língua e cultura de interesse. 0 princípio 
TANDEM: pedalando juntos em espanhol e português

dessa parceria é, então, o mesmo do de um passeio de bicicleta tandem: ambos devem estar pedalando em direção ao mesmo objetivo para não cair!

Assim, o projeto de extensão TANDEM: Pedalando juntos em espanhol e português está sendo desenvolvido na Universidade Federal da Integração Latino-americana (UNILA), dentro da Área de Línguas e do Ciclo Comum, com o intuito de promover a aprendizagem solidária de português e de espanhol.

\section{Contextualização}

A UNILA é uma universidade federal brasileira que já desponta no âmbito internacional: situada na tríplice fronteira entre Paraguai, Argentina e Brasil, ela foi fundada tendo como línguas oficiais o espanhol e o português. Mais do que isso, o Plano de Desenvolvimento Institucional (PDI) da UNILA registra como princípios da instituição o bilinguismo, a integração e a solidariedade. No seu documento fundacional, prevê-se que $50 \%$ dos alunos sejam brasileiros, enquanto os outros $50 \%$ deverão vir de distintos países latino-americanos que têm o espanhol como uma das línguas oficiais.

Na busca do bilinguismo, então, o Ciclo Comum dessa Instituição de Ensino Superior (IES) oferece aos discentes, no início de todos os seus cursos, três semestres de aulas de línguas: os alunos brasileiros se dedicam ao estudo do espanhol, ao passo que seus colegas oriundos dos demais países latino-americanos aprenderão a língua-cultura brasileira. Essas disciplinas têm a carga horária de 8 horas semanais e são ministradas, em geral, em paralelo. Enquanto o grupo de alunos hispano-falantes está estudando português, seus companheiros brasileiros estão, na sala ao lado, estudando espanhol.

Essa organização nos permitiu, como veremos nas próximas seções, propor o tandem face a face. Diferentemente de outros grupos que possuem um projeto de tandem no Brasil e enfrentam as tradicionais dificuldades dos encontros de tandem, que envolvem as novas tecnologias e são a distância, por nossa localização sociogeográfica particular, nos é possível, mais do que o e-tandem, propor encontros presenciais de tandem entre falantes nativos de espanhol e de português.

Finalmente, para além da Universidade, toda nossa região de tríplice fronteira aponta para a necessidade de um trabalho intenso na busca do bilinguismo e da intercompreensão de línguas-culturas. Ao mesmo tempo, é incoerente assumir que professores, alunos e comunidade dependam unicamente dos cursos regulares de línguas para alcançar proficiência na sua língua estrangeira/adicional. Consequentemente, nosso público tem grande carência de outros 
TANDEM: pedalando juntos em espanhol e português

recursos de aprendizagem, e esse Projeto de Extensão se propõe a oferecer uma das muitas soluções possíveis a esse desafio.

\section{Marco teórico}

0 tandem diferencia-se de um curso de conversação comum por se tratar de um encontro com objetivos linguísticos e culturais claros, propiciado dentro de um contexto autêntico de comunicação entre dois falantes nativos ou competentes. Ao mesmo tempo, não se trata de uma aula particular de língua estrangeira com um professor que poderia ser chamado de especialista. Ambos os aprendizes construirão seu conhecimento linguístico e cultural em parceria: "eles usarão a língua para compartilhar ideias, opiniões e informação cultural (...) e suas visões de mundo. Cada um deles tentará autonomamente aprender [a língua do outro] e tentará usar a língua em conversas reais, enquanto é ajudado pelo seu/sua colega mais proficiente" (VASSALLO; TELLES, 2006).

Como se pode perceber, o tandem, como ferramenta de ensino, pode ser enquadrado nas mais recentes teorias sociointeracionistas. Vygotsky e Bakhtin, ao colocarem a cultura e a linguagem na constituição social do sujeito e do conhecimento, influenciaram fortemente o ensino de Língua Estrangeira (LE). Para ambos, a língua é um produto de atividades sociais, resultante de interações entre interlocutores, portanto, o ensino de LE não pode deixar de considerar a língua em contexto. Em consonância, o tandem baseia-se no pressuposto de que, nas interações entre os tandenistas, "o conhecimento (da língua, da cultura, do outro) é socialmente co-construído na interação entre os parceiros, por meio da linguagem" (TELLES; MAROTI, 2008).

Mais do que isso, o aprendizado em tandem permite que os conteúdos sejam estabelecidos a partir das necessidades individuais de cada aluno (TELLES; VASSALLO, 2006). E ao mesmo tempo, o parceiro em tandem mais proficiente, ao pensar em maneiras e estratégias de aprendizagem que ajudem seu colega, estará refletindo sobre a própria maneira de aprender. Consequentemente, esse processo de reflexão consciente garantirá, em longo prazo, o despertar de um cidadão (aluno e/ou trabalhador) mais responsável pelo seu papel central de sujeito-ator no processo de criação/compartilhamento do conhecimento.

Ainda, do ponto de vista dos Estudos Culturais, ao colocar o aluno de uma língua estrangeira em contato direto com um falante nativo, que trará consigo e compartilhará uma bagagem de língua e cultura única, o tandem permite trocas muito mais significativas. Dessa maneira, para além da aprendizagem puramente linguística, os dois tandenistas se envolvem em um diálogo intercultural verdadeiramente relevante. 
TANDEM: pedalando juntos em espanhol e português

Finalmente, a relação simétrica entre os dois participantes do diálogo também contribui para que essa troca tenha resultados positivos. Diferentemente da intervenção em sala de aula, onde o aluno pode recear a crítica do professor ou ser avaliado pelos colegas, nas sessões de tandem, ambos encontram-se na mesma posição. Como aprendiz, o aluno se sente mais confiante e, inversamente, no momento em que será o falante mais competente, terá mais claramente consciência do papel do outro e estará mais preparado para agir eticamente, em ambas as situações. Brammerts (1995 apud GÓIS, 2009), de fato, assinala que "como ambos os parceiros passam pela experiência de serem aprendizes de uma língua, eles têm mais facilidade do que outros aprendizes em lidar com os problemas de seu parceiro com um maior grau de sensibilidade, paciência e compreensão".

\section{Objetivos do projeto}

Nossa proposta é, sobretudo, uma proposta de mediação: colocamos em contato falantes nativos de espanhol e português, línguas oficiais da UNILA, para que estes, conversando, estudem e aprendam a língua do outro de maneira autônoma e solidária, focando na interação oral, na conversação e na comunicação autênticas. Para tal, dirigimos nosso trabalho para três objetivos: (1) divulgar a ferramenta de aprendizagem solidária e autônoma, tandem; (2) colocar falantes de espanhol e português em contato para o ensino-aprendizagem de línguas de forma complementar às aulas tradicionais; e (3) auxiliar os aprendizes nas dúvidas de língua/cultura e metodologia/estratégias de ensino-aprendizagem durante seus encontros.

Além disso, nosso projeto se coloca como uma das instâncias de aplicação do projeto de pesquisa "Português e espanhol pedalando juntos: a relevância da aprendizagem em tandem para o fortalecimento do bilinguismo em línguas próximas". Nesse sentido, a experiência prática de tal programa fornece dados contínuos para a revisão e aperfeiçoamento desse recurso pedagógico e para a revisão e reedição de um manual de tandem guiado para aprendizagem de línguas em autonomia, que foi produzido e está sendo distribuído em formato e-book, para toda a comunidade.

\section{Metodologia}

O tandem diferencia-se de um curso de conversação comum por se tratar de um encontro com objetivos linguísticos e culturais claros, propiciado dentro de um contexto autêntico de comunicação entre dois falantes nativos ou competentes. Ao mesmo tempo, não se 
TANDEM: pedalando juntos em espanhol e português

trata de uma aula particular de língua estrangeira com um professor que poderia ser chamado de especialista. Ambos os aprendizes construirão seu conhecimento linguístico e cultural em parceria: "eles usarão a língua para compartilhar ideias, opiniões e informação cultural (...) e suas visões de mundo. Cada um deles tentará autonomamente aprender [a língua do outro] e tentará usar a língua em conversas reais, enquanto é ajudado pelo seu/sua colega mais proficiente" (VASSALLO; TELLES, 2006).

\subsection{Primeiras pedaladas nas aulas de Português Língua Estrangeira (PLA) e Espanhol Língua Estrangeira (ELA)}

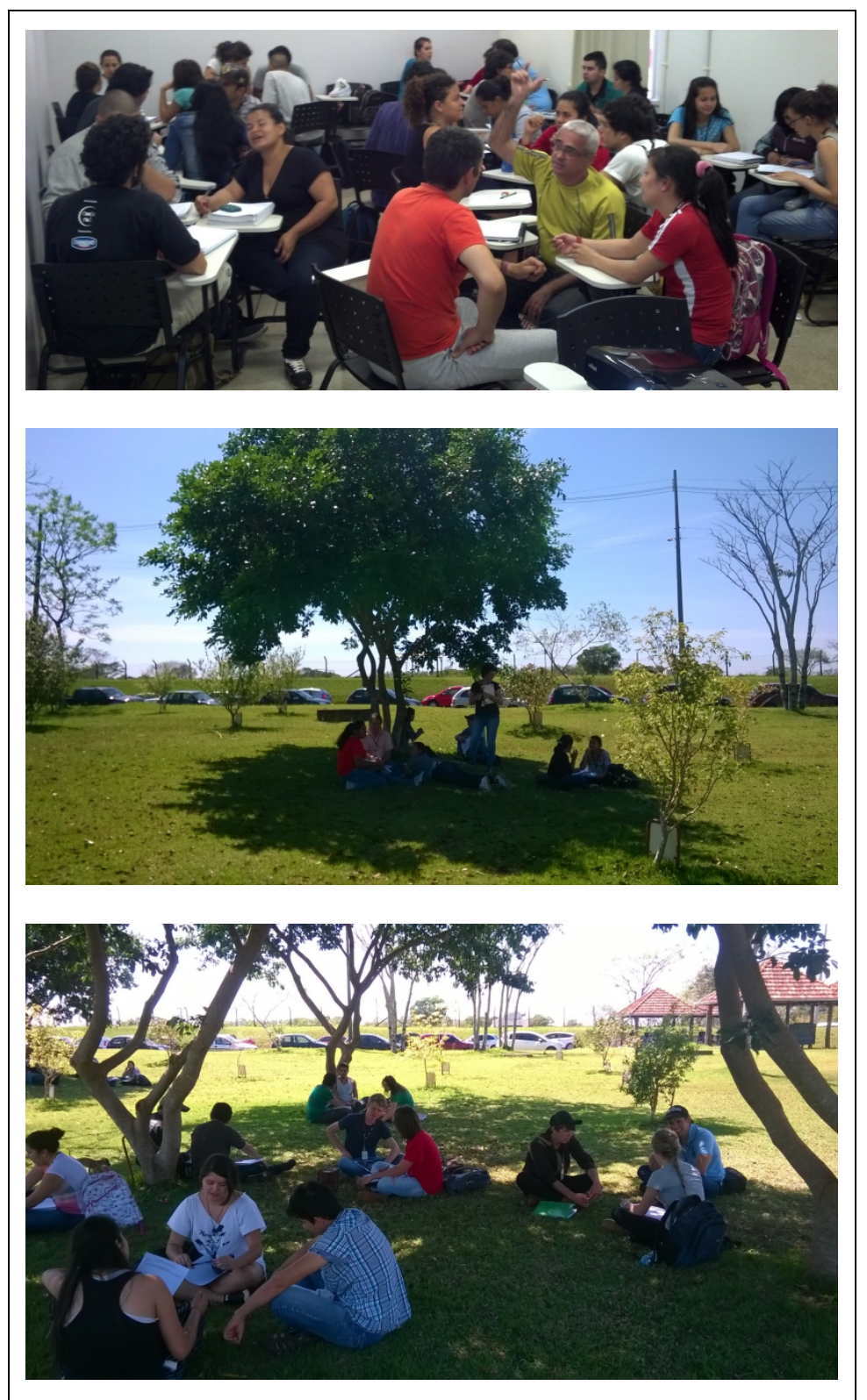

Ilustração 2: Tandem sala de aula vs. área verde Fonte: tandemunila.com.br (Licença CC-BY-NC) 
TANDEM: pedalando juntos em espanhol e português

$\mathrm{Na}$ área de Línguas, um grupo de professores se mostrou interessado em experimentar a integração do tandem em suas aulas. Em um primeiro momento, professores de espanhol e português formaram parcerias e, assim, reuniram suas turmas, no horário de aula, para apresentar esse recurso e formar os pares de tandenistas.

Ao longo do semestre, então, as duas turmas se uniam semanalmente, durante uma ou duas horas, para as sessões. Esses encontros eram monitorados por ambos os professores, que criavam e sugeriam atividades em conjunto, algumas relacionadas com os temas e tópicos do curso. A cada semana, em aulas alternadas, professores conversavam com suas respectivas turmas, levantando sugestões de mudança, que eram aplicadas nos encontros subsequentes.

Mais do que uma situação autêntica de comunicação que encantou e motivou os alunos, o tandem permitiu que os professores extrapolassem as paredes das salas de aula, realizando aulas na área verde da Universidade, e possibilitou que tópicos sensíveis e questões culturais significativas fossem discutidos, modificando profundamente as relações entre os discentes de diversas nacionalidades.

\subsection{Primeiras pedaladas no programa de extensão}

No Projeto de Extensão, especificamente, a coordenadora do projeto e as duas monitoras organizaram, ao longo do segundo semestre letivo de 2014, encontros semanais nas segundas (18h), quartas (8h, 12h e 18h), quintas (18h) e sextas-feiras (8h), nos campi UNILA-Centro e UNILA-Parque Tecnológico Itaipu (PTI). Esses encontros eram abertos para os funcionários da Universidade, da Itaipu e da comunidade da tríplice fronteira. Como mencionamos anteriormente, além de divulgar o projeto, os encontros tinham o propósito de oferecer um momento e um espaço de auxílio aos parceiros de tandem, para que estes tivessem sucesso no desenvolvimento de seu aprendizado autônomo e pudessem conversar sobre suas dúvidas de língua/cultura.

Inicialmente, contudo, divulgamos o projeto na $w e b$, na Itaipu e na Universidade, solicitando aos interessados que preenchessem uma ficha de cadastro online, onde deveriam mencionar seu nível de língua, seus interesses e sua disponibilidade, entre outras informações. Esse primeiro contato a distância nos permitiu encontrar dois companheiros que poderiam formar uma parceria interessante e, então, convidávamos os dois para os encontros presenciais.

No primeiro encontro presencial, as parcerias recebiam um "kit didático", contendo um guia simplificado dos princípios e regras do tandem, modelos de fichas de acompanhamento e de avaliação e algumas propostas de atividades de conversação. Nos encontros seguintes, as parcerias trabalhavam autonomamente. Além disso, a cada reunião, os professores- 
TANDEM: pedalando juntos em espanhol e português

coordenadores e monitoras forneciam atividades extras de conversação sobre tópicos de língua e cultura para os alunos que as solicitavam, bem como auxiliavam a estes em suas dúvidas.

É possível dizer que esse projeto suscitou bastante interesse nas cidades vizinhas do Paraguai e da Argentina, assim como de pessoas não ligadas à comunidade acadêmica, que se mostraram entusiasmadas em ter encontros reais com pessoas de outros países e em ter um contato mais relevante e autêntico com sua língua-cultura.

\subsubsection{Organização das sessões}

Nas diretrizes iniciais, os tandenistas eram aconselhados a se encontrar durante uma ou duas horas e a conversar metade do tempo disponível em cada uma das duas línguas, sem, contudo, misturá-las. Durante as sessões de tandem de duas horas, então, os parceiros eram aconselhados a dividirem o tempo de cada língua em três momentos: conversação (30-40 minutos); feedback de língua/cultura (10-20 minutos) e (auto) avaliação (10 minutos).

Durante a conversação, os tandenistas deveriam discutir livremente vários temas de escolha aberta. Eles eram incentivados a falarem mesmo se não se sentissem muito seguros. Se não soubessem como dizer algo, por exemplo, eram estimulados a se esforçar para se comunicar: fazendo gestos, usando outras palavras, desenhando etc. Na sequência, durante o feedback de língua/cultura, os tandenistas eram incitados a corrigir o parceiro, usando para isso as anotações que teriam feito durante a parte de conversação livre. Guias de controle e de registro de aprendizagem foram entregues para tandenistas e estão disponíveis no e-book “TANDEM: guia para uma aprendizagem solidária".

Nos minutos finais, os tandenistas eram impulsionados a pensarem sobre o próprio progresso na língua estrangeira, expressando suas dificuldades e mencionando eventuais avanços. Ambos os parceiros deveriam, igualmente, avaliar o encontro, discutir o tipo de atividade, se ela foi interessante, se funcionou para os objetivos desejados, e pensar em atividades ou melhorias para o próximo encontro.

\subsection{Outras ações}

Com o intuito de ampliar o projeto, foram ofertadas, igualmente, duas oficinas abertas à comunidade e a outras universidades da região, para formação de monitores/professores de tandem. A primeira foi um atelier de formação de monitores, realizado pela professoracoordenadora, em setembro de 2014, tendo como público alunos da Universidade Estadual do 
TANDEM: pedalando juntos em espanhol e português

Oeste do Paraná (UNIOESTE) e da UNILA. A segunda intervenção aconteceu durante o VIII Encontro Internacional de Letras (UNILA e UNIOESTE), em outubro de 2014. Nesse encontro, a professora-coordenadora, Laura Ferreira (UNILA), e a professora Gabriela Diniz (CELIN-UFPR) ofereceram um atelier de introdução ao tandem, tendo como público alunas e professoras de universidades argentinas e brasileiras.

Além disso, as colegas Larissa Tirloni (UNIOESTE) e Fernanda Chichorro (UTPFR), em conjunto com o coordenador adjunto, com as monitoras e com os orientandos de iniciação científica, desenvolveram, em português e espanhol, a primeira versão do manual TANDEM: guia para uma aprendizagem solidária/TÁNDEM: guía para un aprendizaje solidário, disponibilizado no site http://www.tandemunila.com.br igualmente criado durante o projeto.

\section{Discussão dos resultados}

Os frutos desse projeto foram muitos e formidáveis: a publicação do e-book foi, certamente, de grande relevância para a continuidade do projeto e para a divulgação do tandem como ferramenta de aprendizagem de línguas na América Latina. Ainda, observamos grande aceitação e interesse da comunidade: apesar da restrita divulgação, interessados das três cidades fronteiriças, mesmo distantes da Universidade, ficaram sabendo do projeto e buscaram participar. Por esse motivo, o projeto, que continua em 2015, decidiu expandir seus locais de encontro.

Muitos aprendizados como esse foram recolhidos por meio das diversas enquetes realizadas, assim como do testemunho dos participantes e das monitoras no final de 2014. Entre os alunos, talvez, o resultado mais relevante tenha sido a mudança nas relações e concepções culturais associadas a discentes de diversas nacionalidades latino-americanas. Embora a UNILA seja um espaço onde essas identidades convivem, não é rara a existência de guetos, e as trocas interculturais continuam sendo uma barreira para uma integração real.

Para os professores de línguas, o mais saliente foi o progresso dos alunos na expressão oral. Um professor que inseriu o tandem em uma de suas turmas, mas não em outra, por questões práticas como o horário e a falta de um professor parceiro, relatou que era visível a evolução daqueles que tiveram a oportunidade de conversar com um falante nativo de espanhol, em encontros individuais.

0 projeto ainda está crescendo, e os frutos positivos que colhemos em seu primeiro ano nos motivaram a continuar trabalhando para aperfeiçoar o programa, ao longo de 2015. 


\section{Referências}

ARAÚJO, D. (2014) Nos caminhos da integração e da interculturalidade: os desafios da UNILA. in Revista SURES, n. 3, 2014.2 Disponível em: <https://ojs.unila.edu.br/ojs/index.php/sures/article/view/173>.

ARAUJO, N.R.P. (2012) Formação de parcerias de teletandem: Da organização ao sistema de atividades. Dissertação de Mestrado. UNESP - P.P.G. em Estudos Linguísticos, 2012. Orientadora: Dra. Solange Aranha, 2012.

BENEDETTI, A.M.; CONSOLO, D.A.; VIEIRA-ABRAHÃO, M.H. (2010) Pesquisas em Ensino e Aprendizagem no Teletandem Brasil: Línguas estrangeiras para todos. Campinas, Pontes Editores, 2010.

DE SOUZA, 0. (2001) Abordagens fenomenológico-hermenêuticas em pesquisas educacionais. Revista Contrapontos, v. 1, n. 1. 2001, p. 31-38.

DUARTE, P. A. P. (2013) 0 espanhol no Brasil: "problemas e perspectivas". Trabalho de Conclusão de Curso (Graduação em Letras - Habilitação em Língua Espanhola) - Universidade Estadual da Paraíba, Campina Grande, 2013.

GÓIS, E. R. As diferenças culturais no teletandem. Relatório final de bolsa PIBIC - Reitoria UNESP. Faculdade de Ciências e Letras de Assis. Orientador: Dr. João A. Telles, Departamento de Educação, 2009.

KIPPER, E. (2013) Aquisição de segunda língua em contextos de bilinguismo societal. Letrônica: Revista Digital do PPGL, v. 5, n. 3, p. 88-102, 2013.

TELLES, J.A.; MAROTI, F.A. (2008) Teletandem: Crenças e respostas dos alunos. In PINHO, S.Z. e SAGLIETTI, J.R.O.C. NÚCLEOS DE ENSINO DA UNESP: Artigos dos projetos realizados em 2006. São Paulo: Cultura Acadêmica Editora, 2008.

TELLES, J. A. \& VASSALLO, M.L. (2006) Foreign language learning in-tandem: Teletandem as an alternative proposal in CALLT. The ESPecialist, v. 27(2). PUC-SP, 2006, p.189-212.

VASSALLO, M.L. \& TELLES, J. A. (2006) Foreign language learning in-tandem: Theoretical principles and research perspectives. The ESPecialist, v. 27(1), Brasil, PUC-SP, 2006, p. 83 118.

UNIVERSIDADE FEDERAL DA INTEGRAÇÃO LATINO-AMERICANA. Projeto de Desenvolvimento Institucional 2013-2017. UNILA: Foz do Iguaçu, 2013a. Disponível em: <http://www.unila.edu.br/sites/default/files/files/PDI\%20UNILA\%202013-2017.pdf.>.

YONEMURA, M. Teacher conversations: A potential source of their own professional growth. In Curriculum Inquiry, p. 239-256. Ontario: John Wiley \& Sons, 1982.

ZOPPI-FONTANA, M.G. \& DINIZ, L.R.A. (2008) Declinando a língua pelas injunções do mercado: institucionalização do português língua estrangeira (PLE), in Estudos Lingüisticos, São Paulo, v. 37, n. 3, p. 89-119, set.-dez. 2008. 
TANDEM: pedalando juntos em espanhol e português

\section{TANDEM: riding together in Spanish and} Portuguese

\begin{abstract}
This project coordinates face to face tandem meetings, where half of the participants are Spanish speakers and the other half Portuguese speakers. With regard to the formation of our tandem learners, we contribute to the establishment of an environment where they can practice and improve an autonomous learning model focused on oral interaction and communication. Our main goal, however, is to offer our community a space to strengthen the Portuguese-Spanish bilingualism, sought more promptly in UNILA, and ideologically throughout Latin America. This is a pilot program for future institutionalization of the tandem as a complementary tool for language learning at the University. Finally, we provide continuous data for a research project dedicated to the review and improvement of this teaching resource.
\end{abstract}

\section{Keywords}

Tandem; Solidary learning; Autonomy; Orality.
TÁNDEM: pedaleando juntos en español y português

\begin{abstract}
Resumen
Este proyecto organiza reuniones de tándem cara a cara, donde la mitad de los participantes son de habla hispana y la otra mitad de habla portuguesa. Con respecto a la formación de nuestros alumnos en tándem, contribuimos a la creación de un ambiente en el que puedan practicar y mejorar un modelo de aprendizaje autónomo centrado en la interacción oral y en la comunicación. Nuestro principal objetivo, sin embargo, es ofrecer a nuestra comunidad un espacio para fortalecer el bilingüismo españolportugués, buscado con mayor prontitud en la UNILA, y ideológicamente en toda Latinoamérica. Este es un programa experimental para la futura institucionalización del tándem como una herramienta complementaria para el aprendizaje de idiomas en la Universidad. Finalmente, ofrecemos datos continuos para un proyecto de investigación dedicado a la revisión y mejora de este recurso didáctico.
\end{abstract}

\section{Palabras clave}

Tándem; Aprendizaje solidaria; Autonomía; Oralidad.

Original submetido em: 14 maio 2015

Aceito para publicação em: 28 jun. 2015

Sobre a autora:

\section{Valdilena Rammé}

Professora na Universidade Federal da Integração Latino-Americana (UNILA). Bacharel em Letras Francês - ênfase em Estudos Linguísticos (2008) pela Universidade Federal do Paraná, mestra (2012) e doutoranda em Estudos Linguísticos pela mesma Instituição. Em sua tese, investiga as mudanças diacrônicas na representação semântica de verbos e preposições envolvidos na expressão do deslocamento em PB. Na UNILA, coordena a pesquisa Português e espanhol pedalando juntos: a relevância da aprendizagem em tandem para o fortalecimento do bilinguismo em línguas próximas vinculada ao Grupo de Pesquisa Interfaces dos processos e objetos de ensino-aprendizagem de Português e Espanhol como línguas estrangeira e adicional (GP IPOELEA). 